\title{
Air pollution and daily admissions for chronic obstructive pulmonary disease in 6 European cities: results from the APHEA project
}

\author{
H.R. Anderson*, C. Spix**, S. Medina***, J.P. Schouten + , J. Castellsague ${ }^{++}$,

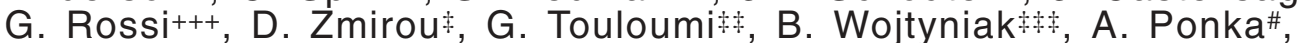 \\ L. Bacharova\#\#, J. Schwartz\#\#\#, K. Katsouyanni $\#$
}

Air pollution and daily admissions for chronic obstructive pulmonary disease in 6 European cities: results from the APHEA project. H.R. Anderson, C. Spix, S. Medina, J.P. Schouten, J. Castellsague, G. Rossi, D. Zmirou, G. Touloumi, B. Wojtyniak, A. Ponka, L. Bacharova, J. Schwartz, K. Katsouvanni. (C)ERS Journals Ltd 1997.

ABSTRACT: We investigated the short-term effects of air pollution on hospital admissions for chronic obstructive pulmonary disease (COPD) in Europe.

As part of a European project (Air Pollution and Health, a European Approach (APHEA)), we analysed data from the cities of Amsterdam, Barcelona, London, Milan, Paris and Rotterdam, using a standardized approach to data eligibility and statistical analysis. Relative risks for daily COPD admissions were obtained using Poisson regression, controlling for: seasonal and other cycles; influenza epidemics; day of the week; temperature; humidity and autocorrelation. Summary effects for each pollutant were estimated as the mean of each city's regression coefficients weighted by the inverse of the variance, allowing for additional between-cities variance, as necessary.

For all ages, the relative risks $\left(95 \%\right.$ confidence limits $(95 \% \mathrm{CL})$ ) for a $50 \mu \mathrm{g} \cdot \mathrm{m}^{-3}$ increase in daily mean level of pollutant (lagged 1-3 days) were $(95 \% \mathrm{CL})$ : sulphur dioxide $1.02(0.98,1.06)$; black smoke $1.04(1.01,1.06)$; total suspended particulates $1.02(1.00,1.05)$, nitrogen dioxide $1.02(1.00,1.05)$ and ozone $(8$ h) 1.04 $(1.02,1.07)$.

The results confirm that air pollution is associated with daily admissions for chronic obstructive pulmonary disease in European cities with widely varying climates. The results for particles and ozone are broadly consistent with those from North America, though the coefficients for particles are substantially smaller. Overall, the evidence points to a causal relationship but the mechanisms of action, exposure response relationships and pollutant interactions remain unclear.

Eur Respir J 1997; 10: 1064-1071.
*Dept of Public Health Sciences, St. George's Hospital Medical School, London, UK. **GSF - National Research Centre for Environment and Health, Institute for Epidemiology, Neuherberg, Germany. ***Observatoire Régional de la Santé, Paris, France. ${ }^{+}$Dept of Epidemiology and Statistics, University of Groningen, The Netherlands. ++Institute Municipal D'Investigacio Medica, Barcelona, Spain. +++ Institute of Clinical Physiology, National Research Council, Pisa, Italy. ‡Faculté de Médicine, Université de Grenoble, France. $¥$ Dept of Hygiene and Epidemiology, University of Athens Medical School, Greece. + National Institute of Hygiene, Warsaw, Poland. \#Helsinki City Centre of the Environment, Finland. \#National Centre for Health Promotion, Bratlslava, Slovakia. \#\#\#Harvard School of Public Health, Boston, USA.

Correspondence: H.R. Anderson, Dept of Public Health Sciences, St George's Hospital Medical School, Cranmer Terrace. London SW17 ORE, UK

Keywords: Air pollution, chronic obstructive pulmonary disease, hospital admissions, meta-analysis

Received: August 121996

Accepted after revision January 221997

This work was supported by the European Community Environment 91-94 programme (Contract EV5V CT 920202; DG XII).
There is considerable evidence that severe air pollution episodes may be associated with an increase in morbidity and mortality [1, 2]. Recent studies have found that daily morbidity and mortality may also be associated with levels of air pollution which are well below those observed in episodes and are within current air quality standards [3]. A vulnerable group is likely to be older people with pre-existing cardiorespiratory disease, including chronic obstructive pulmonary disease (COPD) [1, $3,4]$. This condition is characterized by chronic and usually progressive impairment of airflow due to obstruction, damage and disorganization of the airways, as well as to loss of alveolar tissue. Advanced stages of the disease are associated with poor respiratory reserve, and affected individuals are likely to be especially vulnerable to additional stress on the respiratory system, such as might be caused by the toxic effects of inhaled pollutants. Evidence from panels of patients with COPD suggests that they experience small reductions in lung function in association with increased pollution levels in the ambient range [5, 6]. Hospital admissions for COPD might, therefore, be a sensitive indicator of the adverse effects of outdoor air pollution. Studies from Birmingham (AL, USA) [7], Detroit (MI, USA) [8], Minneapolis-St Paul (MN, USA) [9], Ontario (Canada) [10] and Spokane (WA, USA) [11] have reported associations between daily admissions for COPD and particulate and ozone pollution.

In the Air Pollution and Health, a European Approach (APHEA) collaboration, a standardized prospective approach was used to examine the short-term effects of air pollution on mortality and morbidity in a wide range 
of European cities [12]. In six cities (Amsterdam, Barcelona, London, Milan, Paris and Rotterdam) data on admissions for COPD were analysed. In this paper, we present the results of an analysis, in which the individual city results have been combined using meta-analytical techniques to provide summary estimates of the relative risks of daily admissions for COPD associated with ambient levels of sulphur dioxide $\left(\mathrm{SO}_{2}\right)$, nitrogen dioxide $\left(\mathrm{NO}_{2}\right)$ ozone $\left(\mathrm{O}_{3}\right)$ and particles (black smoke (BS) or total suspended particulates (TSP)). Papers concerned with all emergency respiratory admissions (International Classification of Diseases 9th Revision (ICD9) 460-519) and asthma (ICD9 493) will be published separately.

\section{Methods}

Details of each city's methods have been reported previously [13-17]. From routine sources, daily counts of emergency hospital admissions for ICD9 490 (unspecified bronchitis), 491 (chronic bronchitis), 492 (emphysema) and 496 (chronic airways obstruction) were obtained. For the purpose of this analysis, these four codes comprise COPD. In Barcelona, data collection was part of a special project. The admissions covered all hospitals in each city which admit medical emergencies, except for Barcelona, where six participating hospitals, which cover $90 \%$ of emergencies, provided data on emergency COPD admissions. In Milan and Paris, emergency admissions could not be separated from total admissions, but based on an analysis of London data, which found that $95 \%$ of COPD admissions in that city were "immediate", it is likely that the large majority of COPD admissions in Paris and Milan were also "immediate" i.e. unplanned emergency admissions. The proportion of all medical admissions with diagnostic coding was over $90 \%$ in all cities except London, where it rose from 73 to $95 \%$ during the period of study. These systems record the diagnosis of the condition responsible for admission at the time of discharge.

The effects of pollutants that were already available from routine monitoring systems measuring background concentrations were studied. The criteria for inclusion of monitors and for dealing with missing values were decided in advance by the APHEA group [12]. $\mathrm{SO}_{2}$ and $\mathrm{NO}_{2}$ were analysed as $24 \mathrm{~h}$ and maximum $1 \mathrm{~h}$ means for each day. Indicators of particles used in this analysis were TSP and BS analysed as $24 \mathrm{~h}$ values. Ozone was analysed as an $8 \mathrm{~h}$ mean (09:00 to 17:00 h) and as the daily maximum $1 \mathrm{~h}$ mean. Temperature and humidity were analysed as mean $24 \mathrm{~h}$ values.

The APHEA group agreed the analytical approach in advance to ensure the maximum degree of comparability. This was Poisson time series regression controlling for trend, seasonal and other cycles down to 2 months (6 weeks in the case of London) [15], day of the week, holidays, influenza epidemics, temperature, humidity and autocorrelation [18, 19]. Within the constraints of the agreed approach, each centre analysed their data individually rather than on a pooled basis. This decision was made because factors, such as access patterns, pollution mixtures, climate and seasonal influences differed between cities, and might need to be taken into account on a city by city basis. Similarly, each centre determined for each pollutant the best 1 day lag (up to 3 days) and cumulative lag (the mean over several previous days) for each pollutant. For ozone, up to 5 days were allowed. For centres with higher levels of pollution (days above $200 \mu \mathrm{g} \cdot \mathrm{m}^{-3}$ ), the exposure response was sometimes logarithmic, flattening out at higher levels. To simplify the meta-analysis, each centre fitted a linear relationship between the pollutant and COPD admissions for days below $200 \mu \mathrm{g} \cdot \mathrm{m}^{-3}$. In addition to all year models, coefficients were estimated for the cool (October to March) and warm (April to September) seasons separately.

The summary effect of each air pollution indicator on COPD admissions was estimated by calculating the weighted mean of each city's regression coefficients, the weights being inversely proportional to the local variances. The weights were calculated assuming a fixed effects model when a Chi-squared test failed to detect heterogeneity at the sensitive level of alpha $=20 \%$. When the assumption of homogeneity had to be rejected, a random effects model was adopted; this gives weights which are more similar between cities but a larger variance, reflecting greater uncertainty about the summary estimate when local results are heterogeneous [20].

Where heterogeneity was observed, we tried to explain this using weighted linear regressions of local coefficients on non-time-dependent properties of the cities, including indicators of general population health status, climate, quality of outcome data, quality of pollutant data, and pollutant features, such as heterogeneity in overall levels of pollution within and between cities.

\section{Results}

Table 1 summarizes the health and environmental data used in the analysis. The cities varied considerably in size and environmental characteristics. The median summer temperature ranged from $14^{\circ} \mathrm{C}$ in Amsterdam and Rotterdam to $22^{\circ} \mathrm{C}$ in Milan, and the median winter temperature from $5^{\circ} \mathrm{C}$ in Amsterdam and Rotterdam to $13^{\circ} \mathrm{C}$ in Barcelona. The contrast between summer and winter temperatures (expressed as percentage difference) was greatest for Amsterdam (47\%), Rotterdam (47\%) and Milan (48\%), intermediate for London (30\%) and Paris (29\%), and lowest for Barcelona (16\%). For pollution levels, the highest and lowest cities, respectively, were: $\mathrm{SO}_{2}$, Milan and Amsterdam; $\mathrm{NO}_{2}$, London and Paris; $\mathrm{BS}$, Barcelona and Amsterdam; and $\mathrm{O}_{3}$, Amsterdam and Paris.

The daily number of COPD admissions varied from 1 (Amsterdam and Rotterdam) to 20 (London). The proportion of COPD admissions for patients aged $\geq 65 \mathrm{yrs}$ ranged from $48 \%$ in Paris to $70 \%$ in Barcelona.

Figure $1 \mathrm{a}-\mathrm{e}$ shows, for the $24 \mathrm{~h}$ concentration of each pollutant ( $8 \mathrm{~h}$ for ozone), the relative risks for each city and the summary estimate for an increase of $50 \mu \mathrm{g} \cdot \mathrm{m}^{-3}$ in each pollutant. Table 2 shows the relative risk estimates for single day and cumulative lags, and also includes maximum $1 \mathrm{~h}$ values for $\mathrm{SO}_{2}, \mathrm{NO}_{2}$ and ozone.

The effect of $\mathrm{SO}_{2}$ varied considerably across cities but the summary estimate was significant for the $1 \mathrm{~h}$ measure and borderline significant for the daily mean. 
Table 1. - Summary data for health and environmental variables for the six European cities

\begin{tabular}{|c|c|c|c|c|c|c|c|}
\hline & & Amsterdam & Barcelona & London & Milan & Paris & Rotterdam \\
\hline Population millions & & 0.7 & 1.7 & 7.2 & 1.5 & 6.5 & 0.6 \\
\hline Period of study & & 1977-1989 & 1986-1992 & 1987-1991 & 1980-1989 & 1987-1992 & 1977-1989 \\
\hline \multirow{3}{*}{ COPD admissions ${ }^{\#} \mathrm{n} \cdot \mathrm{day}^{-1}$} & All year & 1.1 & 11 & 20 & 5 & 11 & 1.1 \\
\hline & Cool & 2.0 & 13 & 23 & 6 & 13 & 1.1 \\
\hline & Warm & 1.1 & 9 & 18 & 4 & 10 & 1.1 \\
\hline \multirow[t]{3}{*}{ Temperature ${ }^{\#}{ }^{\circ} \mathrm{C}$} & All year & 10 & 15 & 12 & 14 & 12 & 10 \\
\hline & Cool & 5 & 13 & 9 & 7 & 7 & 5 \\
\hline & Warm & 14 & 18 & 16 & 22 & 17 & 14 \\
\hline \multirow[t]{3}{*}{ Relative humidity\# \% } & All year & 83 & 76 & 73 & 64 & 78 & 83 \\
\hline & Cool & 86 & 75 & 77 & 71 & 83 & 86 \\
\hline & Warm & 80 & 77 & 68 & 60 & 72 & 80 \\
\hline \multirow[t]{3}{*}{$\mathrm{SO}_{2} 24 \mathrm{~h}^{\#} \mu \mathrm{g} \cdot \mathrm{m}^{-3}$} & All year & 21 & 40 & 31 & 53 & 23 & 32 \\
\hline & Cool & 27 & 46 & 32 & 118 & 31 & 41 \\
\hline & Warm & 17 & 36 & 30 & 30 & 18 & 26 \\
\hline \multirow{3}{*}{$\mathrm{SO}_{2} 1 \mathrm{~h}^{\#} \mu \mathrm{g} \cdot \mathrm{m}^{-3}$} & All year & 50 & 60 & & & 47 & 82 \\
\hline & Cool & 59 & 78 & & & 62 & 97 \\
\hline & Warm & 41 & 50 & & & 37 & 70 \\
\hline \multirow[t]{3}{*}{$\mathrm{NO}_{2} 24 \mathrm{~h}^{\#} \mu \mathrm{g} \cdot \mathrm{m}^{-3}$} & All year & 50 & 53 & 67 & & 42 & 52 \\
\hline & Cool & 51 & 53 & 67 & & 43 & 55 \\
\hline & Warm & 48 & 53 & 67 & & 41 & 49 \\
\hline \multirow{3}{*}{$\mathrm{NO}_{2} 1 \mathrm{~h} \# \mu \mathrm{g} \cdot \mathrm{m}^{-3}$} & All year & 75 & 93 & 98 & & 64 & 78 \\
\hline & Cool & 71 & 88 & 96 & & 62 & 78 \\
\hline & Warm & 75 & 97 & 101 & & 67 & 76 \\
\hline \multirow[t]{3}{*}{ BS $24 \mathrm{~h}^{\#} \mu \mathrm{g} \cdot \mathrm{m}^{-3}$} & All year & 6 & 41 & 13 & & 26 & 22 \\
\hline & Cool & 8 & 50 & 15 & & 32 & 23 \\
\hline & Warm & 5 & 35 & 11 & & 22 & 22 \\
\hline \multirow[t]{3}{*}{ TSP $24 h^{\#} \mu \mathrm{g} \cdot \mathrm{m}^{-3}$} & All year & 41 & 155 & & 105 & & 41 \\
\hline & Cool & 40 & 144 & & 131 & & 40 \\
\hline & Warm & 43 & 162 & & 90 & & 43 \\
\hline \multirow{3}{*}{ Ozone $8 \mathrm{~h}^{\#} \mu \mathrm{g} \cdot \mathrm{m}^{-3}$} & All year & 69 & 56 & 28 & & 20 & 61 \\
\hline & Cool & 55 & 36 & 16 & & 9 & 44 \\
\hline & Warm & 82 & 79 & 36 & & 36 & 75 \\
\hline \multirow[t]{3}{*}{ Ozone $1 \mathrm{~h}^{\#} \mu \mathrm{g} \cdot \mathrm{m}^{-3}$} & All year & 77 & 64 & 38 & & 36 & 71 \\
\hline & Cool & 64 & 55 & 26 & & 20 & 56 \\
\hline & Warm & 91 & 86 & 48 & & 57 & 86 \\
\hline
\end{tabular}

COPD: chronic obstructive pulmonary disease; BS: black smoke; TSP: total suspended particulates. \#: median value.

The lags were inconsistent, being either same day or day 2. This heterogeneity was largely from Amsterdam and Rotterdam; there were indications that this was associated with the use of fewer monitoring stations (one compared with three or more in the other cities) and relatively low temperatures.

The effect of particles was more consistent, and the summary estimates for BS and TSP were both statistically significant or borderline significant. The lags varied from same day to day 2 . For increases of $50 \mu \mathrm{g} \cdot \mathrm{m}^{-3}$ in BS and TSP all-age COPD admissions were increased by $3.5 \%$ (95\% CL 1-6) and $2.2 \%$ (95\% CL 1-5), respectively.

Both $24 \mathrm{~h}$ and $1 \mathrm{~h} \mathrm{NO}$ were significantly associated with COPD admissions and the cities tended to be consistent, apart from Amsterdam which was a negative outlier causing heterogeneity in the $1 \mathrm{~h} \mathrm{NO}_{2}$ effects. This heterogeneity could not be explained using the variables described in the Methods section, as there were few differences between Amsterdam and Rotterdam in these respects. The lags varied from 0 to 2 days. An increase of $50 \mu \mathrm{g} \cdot \mathrm{m}^{-3}$ in $24 \mathrm{~h} \mathrm{NO}$ was associated with a $1.9 \%$ increase in admissions (95\% CL 0-5).

The most consistent and significant findings were for ozone, and there was no significant heterogeneity between the cities. The lags varied from 0 to 2 days. A
$50 \mu \mathrm{g} \cdot \mathrm{m}^{-3}$ increase in $8 \mathrm{~h}$ ozone was associated with a $4.3 \%$ (95\% CL 2-7) increase in admissions. With one exception, all the cities had a zero or 1 day lag. The exception was Rotterdam (also the smallest city), which had a lag of 2 days.

In general, the use of cumulative lags did not give stronger effects than single day lags.

Table 3 shows the effects of pollutants in the warm and cool seasons separately. In the warm season, significant or borderline significant effects were observed for $\mathrm{SO}_{2}, \mathrm{NO}_{2}$ and ozone, but not for BS or TSP. In the cool season, marginally significant effects ( $10 \%$ level) were obtained for BS and ozone. The difference in pollution effect between warm and cool seasons was significant only for $8 \mathrm{~h}$ ozone, with a much stronger effect in the warm season.

Too few cities provided analyses of the $\geq 65$ age group to justify meta-analysis of this age group. However, because most other reports of the effects of air pollution on COPD admissions have been confined to this age group, the results will be mentioned here. London, Milan and Paris analysed the effects of $24 \mathrm{~h} \mathrm{SO}$ on this age group; all the relative risks were positive and of similar size: $1.043(\mathrm{NS}), 1.069(\mathrm{p}<0.05)$ and 1.048 $(\mathrm{p}<0.1)$, respectively. All three individual effects were higher than the all-ages summary estimate of 1.022 . 

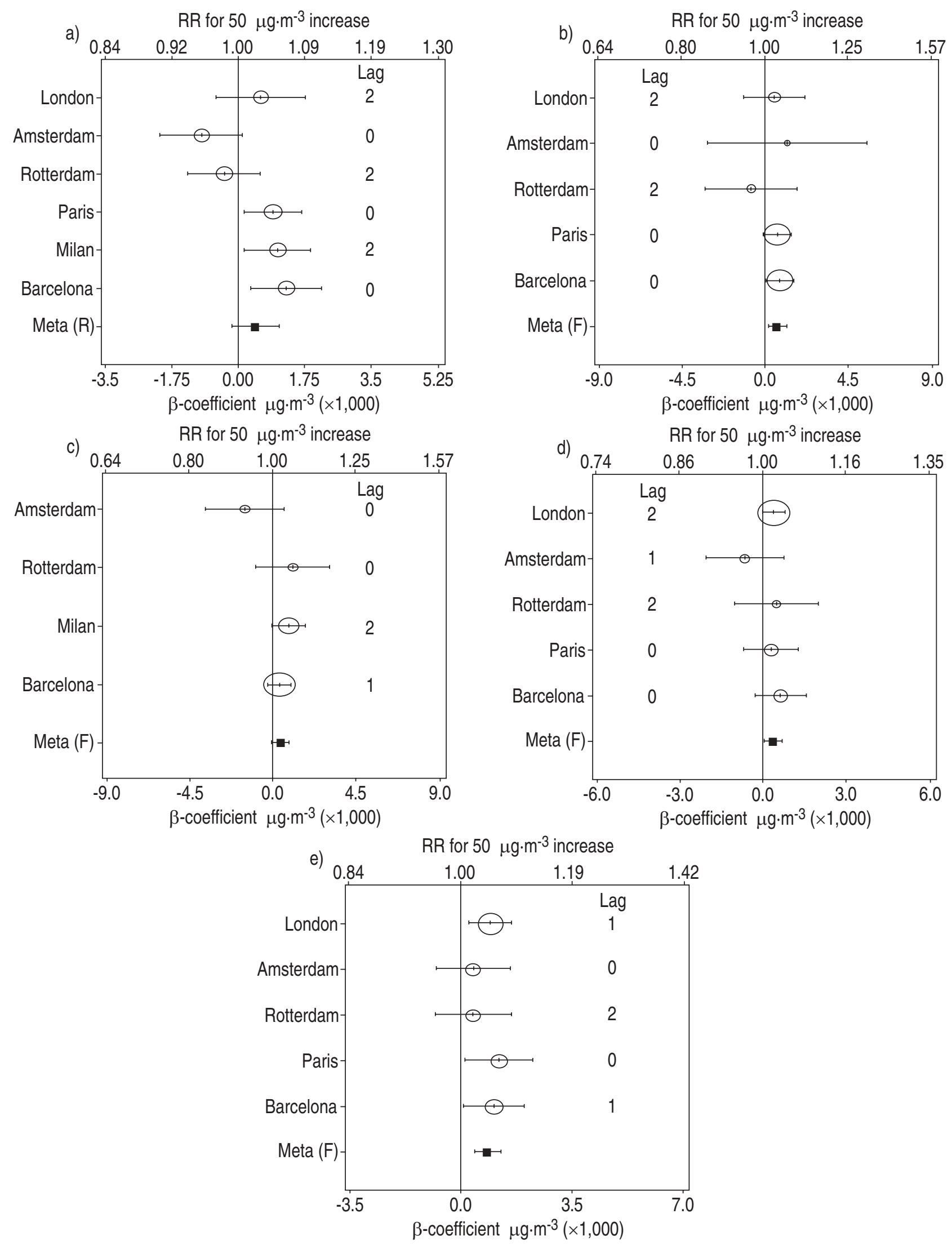

Fig. 1. - Relative risks (RR) and (95\% confidence limits) for daily admissions for COPD, for each city, associated with a $50 \mu$ g.m ${ }^{-3}$ increase in pollutant. Summary estimate from meta-analysis shown as Meta $(\mathrm{F})=$ fixed effects model or Meta $(\mathrm{R})=\mathrm{random}$ effects model. Abscissa show beta-coefficient for log of admissions. The circled area is proportional to the weight attributed to each city in the meta-analysis. a) $24 \mathrm{~h}$ sulphur dioxide; b) $24 \mathrm{~h}$ black smoke; c) total suspended particulates; d) $24 \mathrm{~h}$ nitrogen dioxide; e) 8 h ozone. Lag: effects may be on the same day or lagged up to 3 days (ozone 5 days). 
Table 2. - Summary effects of pollutants on daily emergency hospital admissions for chronic obstructive lung diseases (expressed as relative risk (RR) per $50 \mu \mathrm{g} \cdot \mathrm{m}^{-3}$ increase in pollutant)

\begin{tabular}{|c|c|c|c|c|}
\hline Pollutant & Cities & Lag & $\mathrm{RR}^{\#}$ & $95 \% \mathrm{CL}$ \\
\hline \multirow{2}{*}{$\mathrm{SO}_{2} 24 \mathrm{~h}$} & \multirow[t]{2}{*}{$\mathrm{A}, \mathrm{B}, \mathrm{L}, \mathrm{M}, \mathrm{P}, \mathrm{R}$} & One day & 1.022 & $0.981,1.055$ \\
\hline & & Cumulative & $1.021(*)$ & $0.998,1.045$ \\
\hline \multirow{2}{*}{$\mathrm{SO}_{2} 1 \mathrm{~h}$} & \multirow[t]{2}{*}{$\mathrm{A}, \mathrm{B}, \mathrm{P}, \mathrm{R}$} & One day & 1.011 & $0.994,1.029$ \\
\hline & & Cumulative & $1.015^{*}$ & $1.003,1.027$ \\
\hline \multirow[t]{2}{*}{ BS $24 \mathrm{~h}$} & \multirow[t]{2}{*}{$\mathrm{A}, \mathrm{B}, \mathrm{L}, \mathrm{P}, \mathrm{R}$} & One day & $1.035^{*}$ & $1.010,1.060$ \\
\hline & & Cumulative & $1.038 *$ & $1.008,1.070$ \\
\hline \multirow[t]{2}{*}{ TSP $24 \mathrm{~h}$} & \multirow[t]{2}{*}{$\mathrm{A}, \mathrm{B}, \mathrm{M}, \mathrm{R}$} & One day & $1.022(*)$ & $0.998,1.047$ \\
\hline & & Cumulative & 1.033 & $0.994,1.074$ \\
\hline \multirow{2}{*}{$\mathrm{NO}_{2} 24 \mathrm{~h}$} & \multirow[t]{2}{*}{$\mathrm{A}, \mathrm{B}, \mathrm{L}, \mathrm{P}, \mathrm{R}$} & One day & $1.019^{*}$ & $1.002,1.047$ \\
\hline & & Cumulative & $1.026^{*}$ & $1.004,1.036$ \\
\hline \multirow{2}{*}{$\mathrm{NO}_{2} 1 \mathrm{~h}$} & \multirow[t]{2}{*}{$\mathrm{A}, \mathrm{B}, \mathrm{L}, \mathrm{P}, \mathrm{R}$} & One day & $1.013^{*}$ & $1.003,1.022$ \\
\hline & & Cumulative & 1.014 & $0.976,1.054$ \\
\hline \multirow[t]{2}{*}{ Ozone $8 \mathrm{~h}$} & \multirow[t]{2}{*}{$\mathrm{A}, \mathrm{B}, \mathrm{L}, \mathrm{P}, \mathrm{R}$} & One day & $1.043^{*}$ & $1.022,1.065$ \\
\hline & & Cumulative & $1.056^{*}$ & $1.027,1.086$ \\
\hline \multirow[t]{2}{*}{ Ozone $1 \mathrm{~h}$} & \multirow[t]{2}{*}{$\mathrm{A}, \mathrm{B}, \mathrm{L}, \mathrm{P}, \mathrm{R}$} & One day & $1.029 *$ & $1.011,1.047$ \\
\hline & & Cumulative & $1.049 *$ & $1.024,1.075$ \\
\hline
\end{tabular}

\#: the original Poisson regression coefficient may be calculated by dividing the natural logarithm of the RR by 50. A: Amsterdam; B: Barcelona; L: London; M: Milan; P: Paris; R: Rotterdam; one day lag: effects may be on the same day or lagged up to 3 days (ozone 5 days); Cumulative: effects of mean of same day and up to 3 previous days (ozone up to 5 previous days); $95 \%$ CL: 95\% confidence limits; BS: black smoke; TSP: total suspended particulates. *: $\mathrm{p}<0.05 ;(*): \mathrm{p}=0.05-0.1$.

Table 3. - Summary effects of air pollutants on COPD admissions by "cool" and "warm" season; single day lags only (expressed as relative risk (RR) per $50 \mu \mathrm{g} \cdot \mathrm{m}^{-3}$ increase in pollutant)

\begin{tabular}{|c|c|c|c|c|}
\hline Pollutant & Cities & Season & $\mathrm{RR}^{\#}$ & $95 \% \mathrm{CL}$ \\
\hline \multirow{2}{*}{$\mathrm{SO}_{2} 24 \mathrm{~h}$} & \multirow[t]{2}{*}{$\mathrm{A}, \mathrm{B}, \mathrm{L}, \mathrm{M}, \mathrm{P}, \mathrm{R}$} & Cool & 1.02 & $0.98,1.05$ \\
\hline & & Warm & $1.05 *$ & $1.01,1.10$ \\
\hline \multirow[t]{2}{*}{$\mathrm{SO}_{2} 1 \mathrm{~h}$} & \multirow[t]{2}{*}{$\mathrm{A}, \mathrm{B}, \mathrm{P}, \mathrm{R}$} & Cool & 1.01 & $0.99,1.03$ \\
\hline & & Warm & $1.02 *$ & $1.00,1.04$ \\
\hline \multirow[t]{2}{*}{ BS $24 \mathrm{~h}$} & \multirow[t]{2}{*}{$\mathrm{A}, \mathrm{B}, \mathrm{L}, \mathrm{P}, \mathrm{R}$} & Cool & $1.03(*)$ & $1.00,1.06$ \\
\hline & & Warm & 1.05 & $0.98,1.12$ \\
\hline \multirow[t]{2}{*}{ TSP $24 \mathrm{~h}$} & \multirow[t]{2}{*}{$\mathrm{A}, \mathrm{B}, \mathrm{M}, \mathrm{R}$} & Cool & 1.04 & $0.99,1.09$ \\
\hline & & Warm & 1.01 & $0.98,1.05$ \\
\hline \multirow{2}{*}{$\mathrm{NO}_{2} 24 \mathrm{~h}$} & \multirow[t]{2}{*}{$\mathrm{A}, \mathrm{B}, \mathrm{L}, \mathrm{P}, \mathrm{R}$} & Cool & 1.01 & $0.99,1.03$ \\
\hline & & Warm & $1.03(*)$ & $1.00,1.06$ \\
\hline \multirow{2}{*}{$\mathrm{NO}_{2} 1 \mathrm{~h}$} & \multirow[t]{2}{*}{$\mathrm{A}, \mathrm{B}, \mathrm{L}, \mathrm{P}, \mathrm{R}$} & Cool & 1.02 & $0.99,1.05$ \\
\hline & & Warm & $1.02 *$ & $1.00,1.05$ \\
\hline \multirow[t]{2}{*}{ Ozone $8 \mathrm{~h}$} & \multirow[t]{2}{*}{$\mathrm{A}, \mathrm{B}, \mathrm{L}, \mathrm{P}, \mathrm{R}$} & Cool & $1.03(*)$ & $1.00,1.07$ \\
\hline & & Warm & $1.04 *$ & $1.02,1.07$ \\
\hline \multirow[t]{2}{*}{ Ozone $1 \mathrm{~h}$} & \multirow[t]{2}{*}{$\mathrm{A}, \mathrm{B}, \mathrm{L}, \mathrm{P}, \mathrm{R}$} & Cool & 1.01 & $0.98,1.05$ \\
\hline & & Warm & $1.03 *$ & $1.01,1.05$ \\
\hline
\end{tabular}

For definitions see legends to tables 1 and $2 . *$ : $\mathrm{p}<0.05 ;(*)$ : $\mathrm{p}=0.05-0.1$.

The summary estimate of 1.053 for $\mathrm{SO}_{2}$ for the $\geq 65$ age group was significant $(\mathrm{p}<0.05)$. London and Paris showed similar effects of BS on COPD in the $\geq 65$ age group (1.039 and 1.032, respectively). These effects were not significant and the summary estimate of 1.034 , while not significant, was almost identical to the all-ages summary estimate of 1.035 .

\section{Discussion}

In a prospective standardized study of six European cities, the effect of various air pollutants on daily admissions for COPD were analysed using a Poisson regres- sion technique. Using meta-analytical statistical techniques to combine the individual city effects, it was found that relative risks were significantly increased for a number of pollutants. The most consistent effects were for ozone in the warm season, but significant effects were also observed for $\mathrm{SO}_{2}, \mathrm{NO}_{2}$ and measures of particles (TSP and BS). The concentrations of pollutants were generally well within World Health Organization (WHO) Guidelines for health protection in Europe [21].

This study differs from previous meta-analyses $[3,11]$ in that the meta-analysis was a prospective part of the APHEA project and analysed a wider range of pollutants. The parametric Poisson regression approach chosen has some potential deficiencies. Complex seasonal patterns might not be appropriately modelled by harmonic waves, while other estimates potentially depend on the assumed shape of the exposure response curve [19, $22,23]$. However, investigations into the sensitivity of this approach using different models and comparisons with more sophisticated nonparametric techniques suggest that the approach used in the present study is quite robust $[8,9,24]$. Control for meteorological variables is always a critical issue in temporal air pollution studies. A recent study, which compared the synoptic approach, favoured by some biometeorologists, with controlling for weather variables using the same methods as the APHEA collaboration found that similar results were obtained [25]. The interpretation of the present data should take into account that each centre selected the lag which gave the greatest effect, rather than a priori. This policy was agreed because at the outset of the study there was insufficient epidemiological or biological information upon which to base an a priori hypothesis as to lag, and there was the strong possibility that different environments and health care systems might be associated with different lags.

The final meta-analysis of the results has to be judged differently from retrospective meta-analyses published previously, as it was planned from the start, and care 
Table 4. - Relative risks (RR) for daily hospital admissions for COPD for a $50 \mu \mathrm{g} \cdot \mathrm{m}^{-3}$ increase in pollutant (comparison of APHEA cities with other studies)

\begin{tabular}{|c|c|c|c|c|c|}
\hline City & [Ref $]$ & $\begin{array}{c}\text { COPD } \\
\text { admissions } \\
n \cdot \text { day }^{-1}\end{array}$ & $\begin{array}{r}\mathrm{RR} \text { for } 5 \\
\text { increase in } \\
\text { Particles }\end{array}$ & $\begin{array}{l}\mu \mathrm{g} \cdot \mathrm{m}^{-3} \\
\mathrm{r} \text { pollutant } \\
\text { Ozone }\end{array}$ & Comments \\
\hline \multicolumn{6}{|l|}{ APHEA cities } \\
\hline \multicolumn{2}{|l|}{$\begin{array}{l}\text { Amsterdam, } \\
\text { The Netherlands }\end{array}$} & 1.1 & $\begin{array}{l}1.064^{\ddagger} \\
0.93^{+}\end{array}$ & 1.019 & Emergency admissions, all ages \\
\hline \multicolumn{2}{|l|}{ Barcelona, Spain } & 11 & $\begin{array}{l}1.042^{\ddagger *} \\
1.018^{+}\end{array}$ & $1.053^{*}$ & Emergency room admissions, all ages \\
\hline \multicolumn{2}{|l|}{ London, UK } & 20 & $1.028^{\ddagger}$ & $1.047^{*}$ & Emergency admissions, all ages \\
\hline \multicolumn{2}{|l|}{ Milan, Italy } & 4 & $1.044^{+*}$ & & Emergency and nonemergency admissions, all ages \\
\hline \multicolumn{2}{|l|}{ Paris, France } & 11 & $1.034 \div$ & $1.062 *$ & Emergency and nonemergency admissions, all ages \\
\hline \multicolumn{2}{|l|}{$\begin{array}{l}\text { Rotterdam, } \\
\text { The Netherlands }\end{array}$} & 1.1 & $\begin{array}{l}0.096^{+} \\
1.056^{+}\end{array}$ & 1.019 & Emergency admissions, all ages \\
\hline \multicolumn{2}{|c|}{$\begin{array}{l}\text { APHEA summary estimates } \\
\text { estimates }\end{array}$} & & $\begin{array}{l}1.035^{\ddagger} \\
1.022^{+}(*)\end{array}$ & $1.043^{*}$ & \\
\hline \multicolumn{6}{|c|}{ Other studies } \\
\hline Birmingham, AL, USA & [7] & 2 & $1.12^{\$ *}$ & $1.03^{\dagger}$ & Emergency admissions, $\geq 65$ yrs \\
\hline Detroit, MI, USA & [8] & 5 & $1.20^{\$ *}$ & $1.06^{*}$ & Emergency admissions $\geq 65$ yrs \\
\hline Spokane, WA, USA & [11] & 1 & $1.17 \$ *$ & 1.13 蚶 & Emergency admissions $\geq 65$ yrs \\
\hline Ontario, Canada & {$[10]$} & & $1.07^{++*}$ & & Emergency admissions, all ages \\
\hline Minneapolis, MN, USA & [9] & 2 & $1.25^{\$ *}$ & $1.03 *$ & Emergency admissions $\geq 65$ yrs \\
\hline
\end{tabular}

\#: median value; $\$$ : black smoke; ${ }^{+}$: total suspended particulates; $\$$ : particulate matter with aerodynamic diameter $\leq 10 \mu \mathrm{m}(\mathrm{PM} 10)$; †: $1 \mathrm{~h}$ ozone; + : ozone only measured in 7 warm months of the year; ${ }^{++}$: based on $\mathrm{SO}_{4} / \mathrm{PM} 10=0.40$ [11]. Note that in London, $\mathrm{UK}, \mathrm{BS} / \mathrm{PM} 10=0.7$; this means that to convert the BS coefficients in APHEA to the PM10 equivalent would mean making them smaller $(\times 0.7)$. APHEA: Air Pollution and Health, a European Approach. For further definitions see legends to tables 1 and 2. $*: \mathrm{p}<0.05 ;(*): \mathrm{p}>0.05<0.01$. (Adapted from [11]).

was taken to ensure standardized procedures where possible. There is no bias in selection of cities for study or subsequent analysis.

The estimate of pollutant exposure, being based on one or several city background monitors was necessarily imprecise because ambient concentrations probably vary throughout the city due to the varying nature of emission sources, topography, air mixing, dispersal and removal processes. Furthermore, indoor levels, which comprise the main exposure, do not necessarily reflect outdoor levels. For example, ozone levels are lower indoors but small particles may penetrate indoors quite easily. Nitrogen dioxide may be higher indoors due to indoor combustion sources. If outdoor levels correlate with indoor levels, then the present estimates will be biased but still represent an association with outdoor air pollution. If, on the other hand, the misclassification is random, the tendency will be for the present effects to be biased towards the null, leading to an underestimate of effects [26].

The diagnosis of COPD is known to be subject to variation both within and between countries [27, 28]. Furthermore, several of the cities in this study included a small proportion of nonemergency admissions. It is possible, therefore, that the clinical spectrum of COPD admissions differed from city to city. This might lead to some variation in the size of the estimate, depending on how misclassification affected the average sensitivity of the group coded as COPD, but we are unable to estimate whether and to what extent this occurs.

Are these effects likely to be causal? Although the associations observed are unlikely to be due to chance, the small size of the relative risks raises the question of whether the results could be explained by unknown confounding factors or inadequate control of known confounders. Being an observational ecological study, such a possibility cannot be disproved; however, the consistency of some of the findings together with reports of significant effects on COPD admissions in North America [7-11] suggests that this is less likely.

Few previous studies of this type have systematically analysed pollution effects by season. We observed that the size and significance of effects tended to differ between cities, though the winter/summer differences were statistically significant for one pollutant (ozone). Seasonal differences might have several explanations. One is that there is a threshold effect, exceeded mainly in one season. A second is that the effect depends on complex interactions with the rest of the pollution mix, which also varies seasonally. A third is that some of the associations observed for a particular pollutant are due to confounding by factors, which themselves vary by season. At present, we have insufficient information to explain this variation.

The other important issue is that of plausibility. Patients with advanced COPD tend towards a state of respiratory failure, in which blood levels of oxygen and carbon dioxide become abnormal and which, in turn, leads to problems in other systems, such as the circulatory system. They are particularly susceptible to acute chest infections. It is plausible that such patients might be made worse by the toxic inflammatory effect of small increases in atmospheric pollution. Experimental chamber studies indicate that both healthy subjects and those with asthma or COPD exhibit considerable individual variability in susceptibility to $\mathrm{SO}_{2}$, ozone and $\mathrm{NO}_{2}$ [29-32]. However, there is little evidence from chamber studies that ambient levels of ozone $[33,34]$ or $\mathrm{NO}_{2}$ [35-39], have clinically significant effects on COPD patients. It is conceivable that the disparity between 
ambient and chamber studies may arise because chamber studies do not involve very severe patients or because they are inadequate for simulating the pattern and duration of ambient exposure or the complex mix of pollutants found in the ambient situation. Panel studies do, however, suggest that patients with COPD may experience small short-term effects at ambient levels of particles, $\mathrm{NO}_{2}$ and $\mathrm{SO}_{2}[5,6]$. It should be noted that, in the ambient situation, the actual exposure of some individuals may be substantially higher or lower than indicated by a background monitor.

Previous North American studies of air pollution and COPD admissions have been concerned mainly with the effects of particles or ozone (table 4). The present findings confirm the presence and scale of effect reported for ozone, and suggest that this is a widespread and fairly consistent phenomenon on both sides of the Atlantic.

The results for particles are less consistent than those for ozone. While the APHEA study found that there are significant effects of particles on admissions for COPD, the coefficients were considerably smaller than in the North American studies.

Most of the North American studies have been confined to the $\geq 65$ yrs age group, whereas $50-70 \%$ of European COPD admissions were in this age group. This could account for some of the transatlantic differences in particle effects but is unlikely to be the main explanation, because in the few European cities where analyses were available for the $\geq 65$ yrs group the coefficients for particles were similar to those for all ages, and the coefficients for $\mathrm{SO}_{2}$, though higher in the $\geq 65$ yrs group, were not significant. Furthermore, the effects of ozone were similar in both continents.

The smaller size of particle effects in Europe may be explained by differences in the chemical nature and size distribution of the particle mixture, as well as by differences in the composition of the whole pollution mixture. There is increasing interest in the role of the fine $(<2.5 \mu \mathrm{m})$ and ultrafine $(<0.1 \mu \mathrm{m})$ fractions, of which a substantial part is composed of chemical particles, such as sulphates, nitrates and acid aerosols [40-42]. These are inadequately indicated by BS or TSP.

We have established that significant associations between air pollution and daily admissions for chronic obstructive pulmonary disease can be detected, and that among the candidate pollutants, the associations with ozone are the strongest and most consistent. Further research is required to examine interactions between pollutants, exposure response relationships and health impact. The comparatively smaller effects of particles in Europe compared with North America should be investigated further by using comparable measurements of particles and taking into account differences in the overall pollution mixture. For the present, our results indicate that current levels of air pollution are likely to be harmful to people with chronic obstructive pulmonary disease and that policies to further reduce air pollution should be continued.

Members of the APHEA collaborative group:

K. Katsouyanni, G. Touloumi, E. Samoli (Greece, Co-ordinating Centre); D. Zmirou, P. Ritter, T. Barumandzadeh, F. Balducci, G. Laham (Lyon, France); H.E. Wichmann, C. Spix (Germany); J. Sunyer,
J. Castellsague, M. Saez, A. Tobias (Spain); J.P. Schouten, J.M. Vonk, A.C.M. de Graaf (The Netherlands); A. Ponka (Finland); H.R. Anderson, A. Ponce de Leon, R. Atkinson, J. Bower, D. Strachan, M. Bland (UK); W. Dab, P. Quenel, S. Medina, A. Le Tertre, B. Thelot, B. Festy, Y. Le Moullec, C. Monteil (Paris, France); B. Wojtyniak, T. Piekarski, D. Rabczenko (Poland); M.A. Vigotti, G. Rossi, L. Bisanti, F. Repetto, A. Zanobetti (Italy); L. Bacharova, K. Fandakova (Slovakia).

\section{References}

1. Ministry of Health. Mortality and morbidity during the London fog of December 1952. Reports on Public Health and Medical Subjects. No. 95. London, HMSO, 1954.

2. Wichmann HE, Mueller W, Allhoff P, et al. Health effects during a smog episode in West Germany in 1985. Environ Health Perspect 1989; 79: 89-99.

3. Dockery DW, Pope CA. Acute respiratory effects of particulate air pollution. Ann Rev Public Health 1994; 15: 107-132.

4. Schwartz J. What are people dying of on high air pollution days? Environ Res 1994; 64: 26-35.

5. Pope CA, Kanner RE. Acute effects of PM10 pollution on pulmonary function of smokers with mild-to-moderate chronic obstructive pulmonary disease. Am Rev Respir Dis 1993; 147: 1336-1340.

6. Higgins BG, Francis HC, Yates CJ, et al. Effects of air pollution on symptoms and peak expiratory flow measurements in subjects with obstructive lung disease. Thorax 1995; 50: 149-155.

7. Schwartz J. Air pollution and hospital admissions for the elderly in Birmingham, Alabama. Am J Epidemiol 1994; 139: 589-598.

8. Schwartz J. Air pollution and hospital admissions for the elderly in Detroit, Michigan. Am J Respir Crit Care Med 1994; 150: 648-655.

9. Schwartz J. PM10, ozone, and hospital admissions for the elderly in Minneapolis-St Paul, Minnesota. Arch Environ Health 1994; 49: 366-374.

10. Burnett RT, Dales R, Krewski D, Vincent R, Dann T, Brook JR. Associations between ambient particulate sulfate and admissions to Ontario hospitals for cardiac and respiratory diseases. Am J Epidemiol 1995; 142: $15-22$.

11. Schwartz J. Air pollution and hospital admissions for respiratory disease. Epidemiology 1996; 7: 20-28.

12. Katsouyanni K, Zmirou D, Spix C, et al. Short-term effects of air pollution on health: a European approach using epidemiological time-series data. The APHEA project: background, objectives, design. Eur Respir J 1995; 8: 1030-1038.

13. Schouten JP, Vonk JM, Graaf Ad. Short-term effects of air pollution on emergency hospital admissions for respiratory disease: results of the APHEA project in two major cities in The Netherlands, 1977-1989. J Epidemiol Community Health 1996; 50 (Suppl. 1): S22-S29.

14. Sunyer J, Castellsague J, Saez M, Tobias A, Anto JM. Air pollution and mortality in Barcelona. J Epidemiol Commun Health 1996; 50 (Suppl. 1): S76-S80.

15. Ponce de Leon A, Anderson HR, Bland JM, Strachan DP, Bower JS. Effects of air pollution on daily hospital admissions for respiratory disease in London between 1987-1988 and 1991-1992. J Epidemiol Commun Health 1996; 50 (Suppl. 1): S63-S70.

16. Vigotti MA, Rossi G, Bisanti L, Zanobetti A, Schwartz J. Short-term effects of urban air pollution on respiratory health in Milan, Italy, 1980-1989. J Epidemiol Commun Health 1996; 50 (Suppl. 1): S71-S75. 
17. Dab W, Medina S, Quenel P, et al. Short-term respiratory effects of ambient air pollution: results of the APHEA project in Paris. J Epidemiology Commun Health 1996; 50 (Suppl. 1): S42-S46.

18. Katsouyanni K, Schwartz J, Spix C, et al. Short-term effects of air pollution on health: a European approach using epidemiologic time series data. The APHEA protocol. J Epidemiology Commun Health 1996; 50 (Suppl. 1): S12-S18.

19. Schwartz J, Spix C, Touloumi G, et al. Methodological issues in studies of air pollution and daily counts of deaths or hospital admissions. J Epidemiology Commun Health 1996; 50 (Suppl. 1): S3-S11.

20. Laird NM, Ware JH. Random effects models for longitudinal data. Biometrics 1982; 38: 963-974.

21. WHO. Air quality guidelines for Europe. European Series, No. 23. Copenhagen: WHO Regional Publications, European Series, No. 23, 1987; 315-326.

22. Moolgavkar SH, Luebeck EG, Hall TA, Anderson EL. Particulate air pollution, sulfur dioxide, and daily mortality: a reanalysis of the Steubenville data. Inhal Toxicol 1995; 7: 35-44.

23. Gamble JF, Lewis RJ. Health and respirable particulate (PM10) air pollution: a causal or statistical association? Environ Health Pespect 1996; 104: 838-850.

24. Health Effects Institute. Particulate air pollution and daily mortality. Replication and validation of selected studies. Phase 1 report of the particle epidemiology evaluation project. Cambridge, MA, Health Effects Institute, 1995.

25. Pope CA, Kalkstein LS. Synoptic weather modelling and estimates of the exposure-response relationship between daily mortality and particulate pollution. Environ Health Perspect 1996; 104: 414-420.

26. Rothman KJ. Modern epidemiology. Boston/Toronto, Little Brown and Co., 1986.

27. Littlejohns P, Ebrahim S, Anderson R. Prevalence and diagnosis of chronic respiratory symptoms in adults. $\mathrm{Br}$ Med J 1989; 298: 1556-1560

28. Burney PG. The effect of death certification practice on recorded national asthma mortality rates. Rev Epidemiol Santé Publique 1989; 37: 385-389.

29. Department of Health Advisory Group on the Medical Aspects of Air Pollution Episodes. Ozone. London, HMSO, 1991.

30. Department of Health Advisory Group on the Medical Effects of Air Pollution episodes. Sulphur dioxide, acid aerosols and particulates in the UK. London, HMSO, 1992.

31. Department of Health Advisory Group on the Medical Aspects of Air Pollution Episodes. Oxides of nitrogen. London, HMSO, 1993.

32. Anonymous. Health effects of outdoor pollution. Committee of the environmental and occupational health assembly of the American Thoracic Society. Am J Respir Crit Care Med 1996; 153: 3-50.

33. Kulle TJ, Milman JH, Sauder LR, Kerr HD, Farrell BP, Miller WR. Pulmonary function adaptation to ozone in subjects with chronic bronchitis. Environ Res 1984; 34: 55-63.

34. Linn WS, Shamoo DA, Venet TG, et al. Response to ozone in volunteers with chronic obstructive pulmonary disease. Arch Environ Health 1983; 38: 278-283.

35. von Nieding G, Krekeler H, Fuchs R, Wagner M, Koppenhagen K. Studies of the acute effects of $\mathrm{NO}_{2}$ on lung function: influence on diffusion, perfusion and ventilation in the lungs. Int Arch Arbeitsmed 1973; 31: 61-72.

36. Kerr HD, Kulle TJ, McIlhany ML, Swidersky P. Effects of nitrogen dioxide on pulmonary function in human subjects: an environmental chamber study. Environ Res 1979; 19: 392-404.

37. Linn WS, Fischer DA, Shamoo DA, et al. Controlled exposures of volunteers with chronic obstructive pulmonary disease to sulfur dioxide. Environ Res 1985; 37: 445-451.

38. Morrow PE, Utell MJ, Bauer MA, et al. Pulmonary performance of elderly normal subjects and subjects with chronic obstructive pulmonary disease exposed to 0.3 ppm nitrogen dioxide. Am Rev Respir Dis 1992; 145: 291-300.

39. Hackney JD, Linn WS, Avol EL, et al. Exposures of older adults with chronic respiratory illness to nitrogen dioxide: a combined laboratory and field study. Am Rev Respir Dis 1992; 146: 1480-1486.

40. Seaton A, MacNee W, Donaldson K, Godden D. Particulate air pollution and acute health effects. Lancet 1995; 345(8943): 176-178.

41. Department of Health Committee on the Medical Effects of Air Pollutants. Nonbiological particles and health. London, HMSO, 1995.

42. Quality of Urban Air Review Group. Airborne particulate matter in the United Kingdom. Birmingham, University of Birmingham, 1996. 